Original Article

Journal of Epilepsy Research pISSN 2233-6249 / eISSN 2233-6257

Received April 28, 2021

Revised June 18, 2021

Accepted June 22, 2021

Corresponding author:

Mysore Narasimha Vranda, $\mathrm{PhD}$

Department of Psychiatric Social Work,

NIMHANS, Bengaluru - 560029 ,

Karnataka, India

Tel. +91-80-26995236

Fax. +91-80-26562121

E-mail; vrindamn@gmail.com or vrandamn@nimhans.ac.in

\title{
Quality of Life and Stigma among Women with Epilepsy during Their Reproductive Years
}

\author{
Pallerla Srikanth, MPhil ${ }^{1}$, Mysore Narasimha Vranda, PhD ${ }^{1}$, Priya Treesa Thomas, PhD', \\ Kenchaiah Raghvendra, DM²
}

Departments of ${ }^{1}$ Psychiatric Social Work, ${ }^{2}$ Neurology, NIMHANS, Bengaluru, India

\begin{abstract}
Background and Purpose: The purpose of this study was to understand the relationship between quality of life and stigma among reproductive age group women with epilepsy.

Methods: A cross-sectional descriptive study was conducted to assess the data from the 49 women with epilepsy from a tertiary care hospital in India. Quality of life was evaluated with the quality of life in epilepsy-31 questionnaire and stigma was evaluated with the stigma scale of epilepsy. Data also included socio-demographic and clinical characteristics.
\end{abstract}

Results: The mean age of the participants was $24.67 \pm 3.72$ years. Quality of life total score $\left(r=-0.485^{\star *}\right)$ and seizure worry domain $\left(r=-0.427^{* *}\right)$ were significantly negatively correlated with stigma total score at $p<0.01$ level. Being uneducated, married, unemployed, having children, having generalized tonic-clonic seizures, duration of illness (>10 years), and consuming levetiracetam, anti-epileptic drug (AED), were the significant contributing factors for low quality of life among women with epilepsy during the reproductive age group. Belonging to lower socio-economic status and taking more than two AEDs were also associated with lower quality of life among women with epilepsy, which are trending towards significance.

Conclusions: The study assessed the relationship between the quality of life and the Stigma scale of epilepsy and demonstrated the impact of stigma and quality of life on socio-demographic and clinical variables of women with epilepsy under the reproductive age group. To enhance the quality of life and reduce the stigma levels among women with epilepsy, some of the modifiable parameters can be considered by the multidisciplinary health care professionals from the findings of the current research. (2021;11:63-71)

Key words: Quality of life, Social stigma, Women, Epilepsy, Reproduction

\section{Introduction}

Epilepsy is a common neurological disorder characterized by seizures. The stigmatizing nature of this disease has been reported to significantly impacting the quality of life (QoL) of a person with epilepsy (PwE), ${ }^{1,2}$ stigma has reported being the most significant barrier to the treatment of a PWE. ${ }^{3}$ In low and middle-economic countries, stigma is an essential contributing factor influencing the management of epilepsy. ${ }^{4}$ The overall lifetime prevalence of epilepsy across the world was 7.60 per 1,000 population, and the incidence rate was 61.4 per 100,000 person-years. The overall lifetime prevalence and incidence rate of epilepsy were higher in low and middle-economic countries than in high-economic countries, 8.75 vs. 5.18 per 1,000 and 139.0 vs. 48.9, respectively. ${ }^{5,6}$ In India, the prevalence rate of epilepsy was 393.4, disability-adjusted life years was 280.6 per 100,000 population, ${ }^{7}$ and as per the national mental health survey, the respondents positive for the generalized tonic-clonic seizure screener-diagnostic instrument developed by the world health organization was $0.3 \% .^{8}$ The overall prevalence of epilepsy in India, between the age group of $30-39$ years was $0.4 \%$, and the treatment gap is around $22 \%$ and $95 \%{ }^{9}$

This chronic neurological disorder causes neurobiological, cognitive, psychological, and social consequences. Such impairments lead to a significant social impact on women across their life cycle stages, predominantly associated with stigma and QoL. Women with epilepsy (WWE) undergoes specific difficulties like sexual and re- 
productive dysfunction, pregnancy, lactation, menopause related, contraception, and mental health aspects, ${ }^{10}$ and also face a lot of psychosocial issues such as balancing the family life, conception, adverse pregnancy, poor drug adherence and poor martial outcome. ${ }^{11}$ Living in the middle economic countries with handling issues like stigma at multiple levels in their lifetime poses a big challenge. Epilepsy has played the negative roles in the stigma associated with QoL factors. PwE is predisposed to have lower QoL compared with healthy individuals. ${ }^{12}$

Among PwE, the females and married patients had reported lower QoL scores; hence it is necessary to study the QoL, especially among WWE. Stigma has accounted for more than the other clinical variables like seizure frequency, seizure severity, and anti-epileptic drug (AED)'s side effects on health-related QoL. ${ }^{13}$ The consequences of this disease, such as stigma, quality of life, morbidity and mortality, will differ across the world depending upon various factors: economic, cultural, social, and community. ${ }^{14}$ Studies suggest that an inverse relationship exists between the QoL and stigma, but there is a research gap evidenced by the dearth of literature on these factors from India among WWE in the reproductive age group. How the stigma will affect the QoL among WwE in their reproductive age group needs to be explored; thus, the current study aimed to understand the relationship between the QoL and stigma among the reproductive age group WWE and to determine how participant's sociodemographic and clinical variables associated with QoL and stigma.

\section{Methods}

\section{Study design}

A cross-sectional research design was adopted to study the relationship between the QoL and stigma among the reproductive age group WWE. A consecutive sampling technique was used to collect the data. It was a descriptive study.

\section{Study population \& settings}

All women of the reproductive age group of patients who have been diagnosed with epilepsy by a neurologist/epileptologist and undergoing treatment at the Department of Neurology (inpatient and outpatient) was the study population. The respondents between 18 and 35 years, having diagnosed with epilepsy based on the International League Against Epilepsy criteria version 2017, ${ }^{15}$ and speaking anyone of the following languages, Kannada, English,
Telugu, and Hindi, were included for the study.

Women with active chronic severe psychiatric illnesses were excluded from the research. A prospective sample of 49 participants was selected from the study population based on the study's inclusion and exclusion criteria. Data collection was carried out from December 2018 to February 2019.

\section{Assessments/measures}

\section{Semi-structured questionnaire}

The researcher prepared a semi-structured questionnaire to gather the patient information about the sociodemographic profile like age, education level, marital status, occupation, and clinical profile like the type of seizure, duration of illness (DOI), medication, and duration of medication.

\section{Quality of life in epilepsy (QoLIE) ${ }^{16}$}

It contains 31 items and has seven subscales: seizure worry (SW), emotional well-being (EWB), energy/fatigue (E/F), cognitive functioning (CF), medication effects (MEs), social functioning (SF), and QoL. Specific question numbers have been allotted to each domain of the scale. Raw scores are obtained using Likert scales and linearly transformed on a 0-100 scale. Greater the score, the better the QoL is. This has been validated in Marathi, Malayalam, Hindi, Telugu, and Kannada speaking populations of India. The internal consistency reliabilities for the multi-item scales ranged from 0.77 to 0.85 . The test-retest score ranged from 0.64 to 0.85 .

\section{Stigma scale of epilepsy (SSE) ${ }^{17}$}

A stigma scale is used to assess the perception of stigma. It has 24 items with five domains, and each domain of SSE ask questions related to the opinion about the feeling of PWE on their ability to control epilepsy (stigma scale of epilepsy domain [SSED] 1), feeling when seeing epileptic seizure (SSED2), opinion about the difficulties faced by the PwE (SSED3), opinion on the feeling of epilepsy (SSED4), and opinion on the prejudice in epilepsy (SSED5) related to relationships, marriage, work, school, and family. Each participant's response is documented on a 4-point rating scale such as "not at all", "a little", "a lot", and "totally" with the marking of score 1-4. It permits the quantification of the perception of stigma experienced by the PwE, and also from the people from the community towards PWE. The internal consistency (Cronbach's coefficient) of the scale was ranged 
Table 1. Sociodemographic and clinical profile of WWE

\begin{tabular}{|c|c|}
\hline Variable & Value $(n=49)$ \\
\hline \multicolumn{2}{|l|}{ Education } \\
\hline Illiterate & $12(24.5)$ \\
\hline Literate & 37 (75.5) \\
\hline \multicolumn{2}{|l|}{ Marital status } \\
\hline Single & $18(36.7)$ \\
\hline Married & $31(63.3)$ \\
\hline \multicolumn{2}{|l|}{ Having children } \\
\hline Yes & $27(55.1)$ \\
\hline No & $22(44.9)$ \\
\hline \multicolumn{2}{|l|}{ Occupation } \\
\hline Unemployed & $23(46.9)$ \\
\hline Employed & $26(53.1)$ \\
\hline \multicolumn{2}{|l|}{ SES } \\
\hline Low & $29(59.2)$ \\
\hline Middle & $11(22.4)$ \\
\hline High & $9(18.4)$ \\
\hline \multicolumn{2}{|l|}{ Religion } \\
\hline Hindu & $40(81.6)$ \\
\hline Muslim & $7(14.3)$ \\
\hline Christian & $2(4.1)$ \\
\hline \multicolumn{2}{|l|}{ Type of seizure } \\
\hline Unknown & $9(18.4)$ \\
\hline Focal & $13(26.5)$ \\
\hline Generalized & $27(55.1)$ \\
\hline \multicolumn{2}{|l|}{ Seizure frequency } \\
\hline Once in less than 2 weeks & $21(42.9)$ \\
\hline Once in a month & $16(32.6)$ \\
\hline Once in 2-3 months & $12(24.5)$ \\
\hline \multicolumn{2}{|l|}{ Last episode of seizure } \\
\hline 1 week ago & $19(38.7)$ \\
\hline 2 to 3 weeks ago & $13(26.5)$ \\
\hline More than 3 weeks ago & $17(34.8)$ \\
\hline \multicolumn{2}{|l|}{ Drug adherence } \\
\hline Yes & $42(85.7)$ \\
\hline No & $7(14.3)$ \\
\hline \multicolumn{2}{|l|}{ No. of AED's } \\
\hline One & $28(57.1)$ \\
\hline Two & $15(30.7)$ \\
\hline More than two & $6(12.2)$ \\
\hline \multicolumn{2}{|l|}{ Medications (AED's) } \\
\hline Nill & $8(16.3)$ \\
\hline Levetiracetam & $24(49.0)$ \\
\hline Phenytoin & $11(22.4)$ \\
\hline Sodium valproate & $6(12.2)$ \\
\hline \multicolumn{2}{|l|}{ Duration of illness } \\
\hline $1-5$ years & $16(32.6)$ \\
\hline $5-10$ years & $24(49.0)$ \\
\hline$>10$ years & $9(18.4)$ \\
\hline \multicolumn{2}{|l|}{ Duration of medication } \\
\hline Nill & $7(14.3)$ \\
\hline $1-5$ years & $19(38.7)$ \\
\hline $5-10$ years & $14(28.6)$ \\
\hline$>10$ years & $9(18.4)$ \\
\hline Age (years) & $24.67 \pm 3.727$ \\
\hline Duration of illness (years) & $0.86 \pm 0.70$ \\
\hline Duration of medication (years) & $1.51 \pm 0.96$ \\
\hline
\end{tabular}

Values are presented as mean \pm standard deviation or number (\%). WWE, women with epilepsy; SES, socio-economic status; AED, anti-epileptic drug. between 0.88 and 0.81 , respectively. The researcher availed the author's permission to use the scales and data was collected by administering the tools individually using the interview method. Patient-reported (self-reported) stigma was assessed and each interview has conducted for 60-90 minutes. The researcher has used the scales which were linguistically validated by the original author for the current study.

\section{Statistical analysis}

The information collected through the questionnaires was checked, coded, and entered into a computer database for statistical analysis. Data were processed using SPSS version 14.0 (SPSS Inc., Chicago, IL, USA). A normality test was done and as data were distributed normally, parametric tests were used to analyze the data.

\section{Ethical clearance}

Institute Ethical Committee-Behavioural Sciences Division approval has been obtained for the current study.

\section{Results}

\section{Sociodemographic and clinical profile (Table 1)}

The sociodemographic and clinical profile of the respondents is shown in Table 1. The respondent's mean age \pm standard deviation was $24.67 \pm 3.72$ years and $75.5 \%$ of the respondents were literates. $63.3 \%$ of the participants were married and $55.1 \%$ had children.

Table 2. Relationship among domains of QoLIE and SSEDT

\begin{tabular}{lcc}
\hline Domains of QoL scale & $\begin{array}{l}\text { Pearson correlation } \\
\text { coefficient value }(r)\end{array}$ & $p$-value \\
\hline SF & -0.193 & 0.183 \\
MEs & $-0.355^{*}$ & 0.012 \\
E & $-0.298^{*}$ & 0.038 \\
CF & $-0.353^{*}$ & 0.013 \\
EWB & $-0.320^{*}$ & 0.025 \\
SW & $-0.427^{\dagger}$ & 0.002 \\
OQoL & $-0.364^{*}$ & 0.010 \\
TQoL & $-0.485^{\dagger}$ & $<0.001$ \\
\hline
\end{tabular}

QoLIE, quality of life in epilepsy; SSEDT, total stigma scale of epilepsy domain; QoL, quality of life; SF, social functioning; MEs, medication effects; $E$, energy; $C F$, cognitive functioning; EWB, emotional well-being; SW, seizure worry; OQoL, overall quality of life; TQoL, quality of life total.

*Significant at the 0.05 level (2-tailed).

"Significant at the 0.01 level (2-tailed). 
Majority of $46.9 \%$ were unemployed. When it comes to the clinical diagnosis $55.1 \%$ were suffering from the generalized seizure with $42.9 \%$ have reported the seizure frequency once in 2 weeks. The mean DOI was $0.86 \pm 0.70$ years. The mean duration of medication was $1.51 \pm 0.96$ years. Majority $57.1 \%$ were taking one AED and small proportion of WWE (16.3\%), were not on any AED's, as they have gone for magico-religious and other non-medical practices for treatment. 14.3\% of WWE were non-adherent to the AED's since the time of advice of AED medication.

Table 3. Relationship between the domains of QoLIE and background variables of WWE

\begin{tabular}{|c|c|c|c|c|c|c|c|c|}
\hline Background variable & SF & $\mathrm{ME}$ & $E$ & CF & EWB & SW & OQoL & TQoL \\
\hline \multicolumn{9}{|l|}{ Education } \\
\hline Illiterate $(n=12)$ & $57.75(19.85)$ & $49.76(23.19)$ & $55.00(20.33)$ & $74.21(23.52)$ & $53.66(23.41)$ & $48.63(19.40)$ & $59.58(16.98)$ & 398.59 (112.9 \\
\hline Literate $(n=37)$ & 71.56 (11.44) & 75.29 (20.68) & 51.89 (14.59) & $82.32(13.06)$ & $72.00(13.13)$ & $64.23(21.28)$ & $63.04(17.74)$ & $480.33(70.80)$ \\
\hline $\mathrm{t}$ ( $p$-value) & $-2.99\left(0.003^{\dagger}\right)$ & $-3.60(0.505)$ & $0.58(0.135)$ & $-1.51\left(0.004^{\prime \prime}\right)$ & $-3.42\left(0.003^{\dagger}\right)$ & $-2.25(0.416)$ & $-0.59(0.768)$ & $-2.97\left(0.003^{\dagger}\right)$ \\
\hline \multicolumn{9}{|l|}{ Marital status } \\
\hline Single $(n=18)$ & $68.44(15.82)$ & $62.89(23.03)$ & $58.33(18.39)$ & 79.06 (16.26) & $69.56(20.81)$ & $62.50(24.97)$ & $70.06(17.35)$ & $470.84(105.52)$ \\
\hline Married $(n=31)$ & $68.03(14.74)$ & $72.52(23.98)$ & 49.35 (13.70) & $81.13(16.56)$ & $66.32(16.12)$ & $59.16(19.90)$ & $57.87(16.15)$ & 454.38 (79.35) \\
\hline $\mathrm{t}$ ( $p$-value) & $0.09(0.927)$ & $-1.37(0.176)$ & $0.94(0.088)$ & $-0.42(0.673)$ & $0.60(0.547)$ & $0.51(0.609)$ & $2.47\left(0.017^{\star}\right)$ & $0.61(0.542)$ \\
\hline \multicolumn{9}{|l|}{ Having children } \\
\hline Yes $(n=27)$ & $67.00(17.04)$ & $62.85(21.09)$ & $57.59(17.56)$ & $76.12(18.67)$ & $67.25(18.56)$ & $59.40(24.11)$ & $66.11(16.86)$ & $456.32(100.76)$ \\
\hline No $(n=22)$ & $69.63(12.22)$ & $76.63(25.02)$ & 46.59 (11.58) & $85.51(11.31)$ & $67.81(17.34)$ & $61.64(18.87)$ & $57.38(17.32)$ & $465.19(74.50)$ \\
\hline $\mathrm{t}(p$-value) & $-0.60(0.104)$ & $-2.80(0.400)$ & $2.52(0.120)$ & $-2.06\left(0.019^{\star}\right)$ & $-1.08(0.799)$ & $-0.35\left(0.047^{*}\right)$ & $1.77(0.649)$ & $-0.34(0.11$ \\
\hline \multicolumn{9}{|l|}{ Occupation } \\
\hline Employed $(n=26)$ & 76.19 (16.01) & $66.38(24.05)$ & $55.00(17.88)$ & 77.81 (17.89) & 67.38 (20.76) & $61.92(22.03)$ & $65.65(16.52)$ & 470.33 (98.83) \\
\hline $\begin{array}{l}\text { Unemployed } \\
\qquad(\mathrm{n}=23)\end{array}$ & 70.43 (13.73) & $71.91(23.83)$ & $50.00(13.48)$ & $63.26(14.16)$ & $67.65(14.31)$ & $53.65(21.68)$ & $58.61(18.06)$ & 435.51 (78.97) \\
\hline $\mathrm{t}$ ( $p$-value) & $0.98(0.328)$ & $-0.80(0.424)$ & $1.09(0.280)$ & $1.17(0.247)$ & $-0.05(0.959)$ & $1.44(0.856)$ & $1.83\left(0.037^{\star}\right)$ & $1.42(0.16$ \\
\hline \multicolumn{9}{|l|}{ Type of seizure } \\
\hline Unknown $(n=9)$ & $82.25(7.50)$ & $91.00(10.24)$ & $48.75(6.29)$ & $83.25(12.31)$ & $75.00(10.00)$ & $67.50(24.02)$ & 73.25 (17.27) & $521.00(67.93)$ \\
\hline Local $(n=13)$ & 74.00 (18.19) & 76.00 (17.76) & $58.75(18.46)$ & $88.88(9.478)$ & $69.50(21.58)$ & $65.50(20.16)$ & $71.00(19.42)$ & $503.63(82.90)$ \\
\hline $\begin{array}{l}\text { Generalized } \\
\quad(n=27)\end{array}$ & 65.41 (13.89) & $65.08(24.66)$ & $51.76(16.16)$ & $78.22(17.40)$ & $66.27(17.80)$ & $58.51(22.04)$ & $59.30(16.40)$ & 444.55 (88.26) \\
\hline $\mathrm{F}$ ( $p$-value) & $72(0.076)$ & $0.74(0.479)$ & $1.50(0.233)$ & $0.48(0.621)$ & $1.82(0.058)$ & $2.81\left(0.014^{*}\right)$ & $0.56(0.573)$ & $2.62(0.08$ \\
\hline \multicolumn{9}{|l|}{ DOI } \\
\hline $1-5$ years $(n=16)$ & $77.75(8.70)$ & $80.17(18.70)$ & $50.42(18.27)$ & $87.50(7.62)$ & 70.67 (13.99) & $57.92(17.76)$ & $63.83(19.09)$ & $488.26(60.46)$ \\
\hline $5-10$ years $(n=24)$ & $66.68(12.74)$ & $67.42(17.54)$ & $53.68(14.61)$ & $81.26(13.17)$ & $64.63(18.34)$ & $60.74(22.14)$ & $60.68(16.92)$ & 455.09 (72.01) \\
\hline$>10$ years $(n=9)$ & $53.00(23.40)$ & $56.00(39.77)$ & $47.50(9.35)$ & $59.17(24.22)$ & $58.00(24.36)$ & $48.50(22.29)$ & $61.50(21.27)$ & 383.67 (142.4) \\
\hline $\mathrm{F}$ (p-value) & $1.44(0.236)$ & $1.23(0.311)$ & $0.37(0.828)$ & $1.65(0.177)$ & $1.04(0.395)$ & $3.54\left(0.014^{\star}\right)$ & $0.27(0.893)$ & $4.05\left(0.007^{\prime}\right)$ \\
\hline \multicolumn{9}{|l|}{ Medication } \\
\hline $\begin{array}{l}\text { Levetiracetam } \\
\qquad(n=24)\end{array}$ & 65.96 (18.03) & 64.96 (28.65) & $51.46(14.02)$ & 77.92 (18.88) & $66.17(16.92)$ & $54.00(22.51)$ & $60.17(18.55)$ & 440.64 (99.88) \\
\hline Phenytoin ( $n=11)$ & 69.45 (11.97) & $69.82(13.91)$ & $58.18(19.14)$ & 83.91 (13.33) & $69.45(20.95)$ & $72.73(20.10)$ & $68.18(17.61)$ & 491.72 (83.33) \\
\hline $\begin{array}{l}\text { Sodium valproate } \\
\qquad(\mathrm{n}=6)\end{array}$ & 71.67 (13.18) & $69.00(20.44)$ & $52.50(20.91)$ & $86.00(13.11)$ & $80.67(5.88)$ & $71.33(17.19)$ & $68.50(18.91)$ & 499.67 (60.66) \\
\hline $\mathrm{F}$ (p-value) & $0.35(0.783)$ & $0.77(0.513)$ & $0.62(0.602)$ & $0.60(0.614)$ & $1.88(0.146)$ & $2.88\left(0.045^{\star}\right)$ & $1.11(0.353)$ & $1.30(0.28$ \\
\hline
\end{tabular}

Values are presented as mean (standard deviation) unless otherwise indicated.

QoLIE, quality of life in epilepsy; WwE, women with epilepsy; SF, social functioning; ME, medication effect; E, energy; CF, cognitive functioning; EWB, emotional well-being; SW, seizure worry; OQoL, overall quality of life; TQoL, quality of life total; DOI, duration of illness. *Significant at the 0.05 level (2-tailed).

'Significant at the 0.01 level (2-tailed). 


\section{Descriptive statistics of QoLIE and SSE}

The mean scores for total QoL (TQoL) were 460.39 \pm 89.14 and total SSED (SSEDT) was 43.0 \pm 6.96 . Among all QoL scale domains, the energy domain has the lowest mean score $(52.65 \pm 16.01)$ and the $C F$ domain have the maximum mean score $(80.37 \pm 16.31)$. About SSE, the highest mean score was for the emotional impact of epilepsy $(13.35 \pm 3.50)$ and the lowest for the sense of control over epilepsy $(2.10 \pm 0.71)$

\section{Relationship between the domains of QoLIE and SSET among WwE (Table 2)}

The SW ( $r=-0.427)$ domain and TQoL ( $r=-0.485)$ of QoLIE had a highly significant negative correlation with SSEDT of SSE at $p \leq 0.01$ level. All QoL domains were negatively correlated with the SSEDT except the SF domain.

\section{Relationship between the domains of QoLIE and background variables of WWE (Table 3)}

SF, CF, EWB, and QoL total domains scores were different in the two groups; literate WWE has reported higher scores when compared with the illiterate WWE. For the overall quality of life, domain score was different in the two groups; single and employed WwE have reported higher scores when compared with the married and un- employed WWE. CF and seizure worry domains scores were different in the two groups; women who have children had reported lower scores when compared with women without children. QoL total domain scores were different in the three groups, which is trending towards the significance ( $p=0.052$ ); lower SES WWE has reported lower scores when compared with the middle and higher SES WWE. EWB domain scores were different in the three groups; women who had generalized seizures have reported lower EWB than other types of seizures.

Seizure worry and QoL total domains scores were different in the three groups; women who had more than 10 years of duration have reported lower seizure worry and QoL total scores when compared with the other two groups. ME domain scores were different in the three groups, which is trending towards the significance $(p=0.052)$; women on one AED's have reported lesser MEs than the other two groups. Seizure worry domain scores were different in the three groups; women taking Levetiracetam AED have reported lesser seizure worry than the other two groups. The results related to the number of AED's and type of medication are to be taken with caution since one of the groups have a very less sample size.

Table 4. Relationship between the domains of SSE and background variables among WWE

\begin{tabular}{|c|c|c|c|c|c|c|}
\hline Background variable & $\begin{array}{l}\text { Sense of control } \\
\text { over epilepsy }\end{array}$ & $\begin{array}{l}\text { Perception towards } \\
\text { seizure }\end{array}$ & $\begin{array}{l}\text { Difficulties in } \\
\text { activities of daily } \\
\text { living due to epilepsy }\end{array}$ & $\begin{array}{c}\text { Emotional impact } \\
\text { of epilepsy }\end{array}$ & $\begin{array}{l}\text { Prejudice related } \\
\text { to epilepsy }\end{array}$ & SSEDT \\
\hline \multicolumn{7}{|l|}{ Marital status } \\
\hline Single $(n=18)$ & $2.06(0.639)$ & $9.06(2.900)$ & $10.72(2.866)$ & $14.67(4.524)$ & 7.33 (2.473) & $43.83(8.820)$ \\
\hline Married $(n=31)$ & $2.13(0.763)$ & $8.52(1.749)$ & $11.71(2.636)$ & $12.58(2.540)$ & $7.58(1.911)$ & $42.52(5.738)$ \\
\hline $\mathrm{t}$ ( $p$-value $)$ & $-0.34(0.510)$ & $0.81\left(0.010^{\dagger}\right)$ & $-1.22(0.380)$ & $2.07\left(0.024^{*}\right)$ & $-0.39(0.933)$ & $0.63(0.133)$ \\
\hline \multicolumn{7}{|l|}{ Having children } \\
\hline Yes $(n=27)$ & $2.00(0.535)$ & $8.77(1.771)$ & $11.68(2.626)$ & $12.95(2.853)$ & 7.55 (1.819) & $42.95(6.290)$ \\
\hline No $(n=22)$ & $2.19(0.834)$ & $8.67(2.572)$ & $11.07(2.841)$ & $13.67(3.990)$ & 7.44 (2.359) & $43.04(7.593)$ \\
\hline $\mathrm{t}$ ( $p$-value) & $-0.90\left(0.016^{\star}\right)$ & $1.64\left(0.043^{\star}\right)$ & $0.77(0.431)$ & $-0.70(0.277)$ & $0.16(0.642)$ & $-0.04(0.861)$ \\
\hline \multicolumn{7}{|l|}{ Number of AED's } \\
\hline One $(n=28)$ & $2.11(0.796)$ & $8.26(1.992)$ & $11.34(3.074)$ & $13.00(3.181)$ & $7.26(2.254)$ & $41.97(7.220)$ \\
\hline Two $(n=15)$ & $2.22(0.441)$ & $10.33(2.784)$ & $11.22(1.986)$ & $15.11(4.986)$ & 8.33 (1.936) & $47.22(6.418)$ \\
\hline$>$ two $(n=6)$ & $1.80(0.447)$ & $9.00(1.581)$ & $11.60(1.140)$ & $12.60(1.817)$ & $7.60(0.894)$ & $42.60(2.608)$ \\
\hline $\mathrm{F}$ ( $p$-value) & $0.56(0.570)$ & $3.48(0.039 *)$ & $0.03(0.971)$ & $1.44(0.246)$ & $0.93(0.400)$ & $2.13(0.129)$ \\
\hline
\end{tabular}

Values are presented as mean (standard deviation) unless otherwise indicated.

SSE, stigma scale of epilepsy; WWE, women with epilepsy; SSEDT, total stigma scale of epilepsy domain; AED, anti-epileptic drug * Significant at the 0.05 level (2-tailed).

'Significant at the 0.01 level (2-tailed). 


\section{Relationship between the domains of SSE and background variables among WwE (Table 4)}

Perception towards seizure and emotional impact of epilepsy domains scores was different in the two groups; single WwE have reported higher scores in both the domains than married WwE. Sense of control over epilepsy and perception towards seizure domains scores were different in the two groups; women who had children have reported lower scores in the sense of control over epilepsy and higher in perception towards seizure.

Perception towards seizure domain scores was different in the three groups; women on one AED's have reported lower scores in perception towards seizure than the other two groups. The results related to the number of AED's is to be taken with caution since one of the groups have a very less sample size.

\section{Discussion}

The current study attempted to understand the relationship between stigma associated with epilepsy and the QoL of WWE in the reproductive age. A study from Bhutan has stated that based upon the geographical setting and income level, the QoLIE-31 scores were different among the countries across the world. ${ }^{18}$ This specifically identified subpopulation of WwE has challenges and difficulties throughout their life span due to illness-related and other psychosocial problems. Female gender is one of the most vital factors ${ }^{19}$ and highest risks ${ }^{20}$ for the lower QoL in epilepsy. A recent study from Portugal has stated that being female is the second significant determinant for the lower QoL. ${ }^{21}$ The three pillars of quality of health care, such as availability, accessibility, and affordability are different in urban and rural communities. ${ }^{8}$ More over when it comes to the rural areas, apart from the above mentioned three factors patients from rural areas come across additional adversities, which impact their QoL.

In our study significant sociodemographic determinants of lower QoL were illiterate, being married, unemployed, and having children. This study confirmed that the status of education had a significant effect on the level of QoL; illiterates had lower scores of QoL compared with literates. Similar findings reported by Shakir and Al-Asadi, ${ }^{22}$ using a case-ADVER study, stated that education level was one of the significant determinants of QoL among WWE. Gebre and Haylay ${ }^{23}$ reported that the level of education was a noteworthy interpreter of the QoL among PwE. A study from south India among adolescents with epilepsy who were evaluated for the QoL using the QoLIE scale has demonstrated a remarkable relationship between education lev- el and QoL. ${ }^{24}$ The differentiation in the QoL due to illiteracy was the potential for the awareness of the illness, significance of treatment and drug adherence, consequences to be faced if failed to do, and the good coping strategies pattern. However, a systematic review by Taylor et al., ${ }^{25}$ has reported that the relationship between health-related QoL and educational status was unclear.

A cross-sectional study from India revealed that being unmarried, single, or widowed were the significant factors for the low QoL. ${ }^{26}$ Due to the existing prevalence of cultural beliefs and stigma in Asian countries, the divorce rate is high among PwE. ${ }^{27}$ Ashwin et al. ${ }^{20}$ explored the determinants of lower QoL among PwE and have reported that being married was identified as a determinant of lower QoL among PwE. Socio-economic status (SES) is also one of the contributing factor which impacted the QoL. In the current study, WWE belonged to lower SES had reported lower QoL when compared with middle SES and high SES. A study from south India has reported that lower per capita was an associated factor for QoL's low score among PWE. ${ }^{26}$

The clinical determinants like a type of seizure (generalized onset), DOI (>10 years), and type of AED (Levetiracetam) were the significant factors for a lower QoL in WWE. Type of seizure was the important clinical dimension that has influenced the QoL for the participants in the current study; generalized onset types of participants have reported lower QoL than focal onset and unknown onset seizures. All the subscales scores of the QoLIE-31 were lower for generalized onset participants than focal onset and unknown onset seizures, except for the energy domain. Considering the type of epilepsy on the QoL, there were mixed findings that patients with generalized onset have reported lower scores. ${ }^{27,28}$ It also affected their social relationships with friends and family members, and workability. ${ }^{27}$ In contrast to the current study findings, patients with local seizures had reported lower QoL scores. ${ }^{29,30}$ Number of AED's is also one of the contributing factors which impact on the QoL.

In the present study, it was reported that differentiation depends upon the number of AED's of the patients. In line with our study, polytherapy was associated with a poor QoL compared with monotherapy. ${ }^{31,32}$ A study from India, which adopts a similar methodology, has stated that a substantial decrease in QoL was observed in a PWE under polytherapy. ${ }^{33}$ Another cross-sectional study from south India that acquired similar scales for the data collection has mentioned that a significant difference was found in the QoL scores among stigmatized and non-stigmatized PWE. ${ }^{34}$

Our findings of the current study suggested that stigma has a sig- 
nificant impact on QoL among WWE in their reproductive years; a significant negative correlation was identified between stigma and QoL among WWE in reproductive years. The results have proven that SSET negatively correlated with all QoL domains except for the SF domain. Robson et al. ${ }^{35}$ explored the relationship between stigma and health related QoL (HRQoL) among adult with non-epileptic seizures (NES). The results revealed moderate inverse correlation between stigma and HRQoL, suggesting higher perception of stigma, contributed to poor HRQoL among adult with (NES). The meta-analysis by Shi et al. ${ }^{36}$ reported social support and QoL, negatively correlated with perceived stigma. Saadi et al. ${ }^{18}$ have suggested that stigma has a variable impact on QoL in PwE in countries of all economic levels. In the current study, it was found that unmarried WwE has reported higher QoL and stigma. The QoL is better among unmarried WWE as they are single and have never been undergone the challenges of marriage-related issues. Being a married woman is an additional challenge for WWE, and they experience more stigma, which could be due to being blamed for non-disclosure of the epilepsy, being discriminated by family of procreation due to epilepsy, fear of rejection from significant family members in family of procreation, perceived negative attitude from the spouse and other family members, adverse pregnancy outcomes and fear of being divorced.

On the other hand, perceived stigma is also high due to lack of awareness about the illness itself, and fear of getting married while having illness could be the predominant contributing factors. Most of the participants in our study have reported that the impact of epilepsy has affected their emotional aspects and difficulty in their activities of daily lives. Hence, interventional programs or epilepsy awareness campaigns are the foremost strategies to enhance the knowledge and change the people's attitude towards the illness and the affected individuals; which leads to stigma reduction and enhance the QoL of the PwE and their families. An interventional community-based study from a rural region in Bolivia revealed enhancing the knowledge levels resulted in improved the attitude and reduction in stigma towards PwE. ${ }^{37}$ Hence, there is the necessity to focus on these social and illness characteristics of the PwE in order to reduce the stigma, which can enhance their QoL. A very recent community-based study from Nigeria has demonstrated the need for countrywide educational programs, which contemplate both the cognitive and affective process, by involving multiple stakeholders like primary care workers, community leaders, spiritual and traditional leaders, in order to reduce stigma and improve HRQoL amongst PwE and their families. ${ }^{38}$ The attitude of individual and the community, and their belief about the illness, and social network related factors are the risk factors for the high levels of stigma among PwE. ${ }^{38,39}$

Epilepsy is manifested by the multi-layered and multifaceted uncertain negative roles on the affected individuals in terms of stigmatization and other psychosocial issues in the community, which causes impairments in various domains of health and hence results in poor QoL. Thus, enhancing the QoL of a PwE is an inevitable component of the management for them. ${ }^{40}$ Lack of a control group is a significant limitation of the study; a control group would be valuable to determine whether epilepsy or the fact that they have any chronic disease contributes to the data results. In summary, the current study demonstrated the impact of both sociodemographic and clinical variables on the QoL and stigma among WwE under the reproductive age group and how they can affect the QoL and stigma independently. To enhance the QoL and reduce the stigma levels among WWE, some of these modifiable parameters can be considered by multi-disciplinary health care professionals. Then more research is also needed to address the psychosocial issues that impact QoL and stigma through in-depth qualitative studies. There is a need for sustainable educational programs to change people's perception of epilepsy by involving different stakeholders.

\section{Limitations}

Less sample size is the attributive factor for the statistical difficulties; the study sample was recruited from a large tertiary care hospital setting; hence, comparison cannot be generalized to the different cultural populations and cannot be generalized to patients with comorbidities conditions and intractable, refractory seizures. The current study adopted a consecutive sampling technique. Multiple comparisons have not performed in this study.

\section{Implications}

The impact of stigma in decreasing the QoL among WwE in reproductive years contributes special attention to the necessity of a multi-disciplinary team approach at different levels, such as at the individual, family, and community level. Clinicians not only focus on the medical model but also on the bio-psycho-social model by collaborating with other allied multi-disciplinary teams to enhance QoL, reduce stigma, and address other psychosocial issues; especially, medical social workers play a vital part in providing psychosocial interventions to change the knowledge, attitude and practice about the illness and it's management to the affected individuals and their fam- 
ilies to enhance the QoL. This will give an insight to the researchers to develop a comprehensive model on contributing factors affecting the QoL among WwE.

\section{Acknowledgements}

The authors thank the participants and their families for contributing their time to participate in this study. Without their kind cooperation, this study would not have been possible. This study was a part of MPhil research, and the UGC-JRF funded it.

\section{References}

1. Kumari $P$, Ram D, Haque Nizamie $S$, Goyal N. Stigma and quality of life in individuals with epilepsy: a preliminary report. Epilepsy Behav 2009; 15:358-61.

2. Whatley $A D$, Dilorio $C K$, Yeager $K$. Examining the relationships of depressive symptoms, stigma, social support and regimen-specific support on quality of life in adult patients with epilepsy. Health Educ Res 2010;25: 575-84.

3. World Health Organization (WHO). Investing in mental health. Geneva: WHO, 2003.

4. Mbuba CK, Ngugi AK, Newton CR, Carter JA. The epilepsy treatment gap in developing countries: a systematic review of the magnitude, causes, and intervention strategies. Epilepsia 2008;49:1491-503.

5. Beghi E. The epidemiology of epilepsy. Neuroepidemiology 2020;54: 185-91.

6. Fiest KM, Sauro KM, Wiebe $S$, et al. Prevalence and incidence of epilepsy: a systematic review and meta-analysis of international studies. Neurology 2017;88:296-303.

7. GBD 2016 Epilepsy Collaborators. Global, regional, and national burden of epilepsy, 1990-2016: a systematic analysis for the Global Burden of Disease Study 2016. Lancet Neurol 2019;18:357-75.

8. Murthy RS. National mental health survey of India 2015-2016. Indian J Psychiatry 2017;59:21-6.

9. Amudhan S, Gururaj G, Satishchandra P. Epilepsy in India II: impact, burden, and need for a multisectoral public health response. Ann Indian Acad Neurol 2015;18:369-81.

10. Bangar S, Shastri A, El-Sayeh H, Cavanna AE. Women with epilepsy: clinically relevant issues. Funct Neurol 2016;31:127-34.

11. Sharma SK, Sardana V, Maheshwari $D$, et al. Problems faced by married women with epilepsy in Indian Scenario: a hospital-based study. Int J Epilepsy 2018;5:80-6.

12. Fawale $M B$, Owolabi MO, Ogunniyi A. Effects of seizure severity and seizure freedom on the health-related quality of life of an African population of people with epilepsy. Epilepsy Behav 2014;32:9-14.

13. Suurmeijer TP, Reuvekamp MF, Aldenkamp BP. Social functioning, psychological functioning, and quality of life in epilepsy. Epilepsia 2001;42:
1160-8.

14. Tran DS, Odermatt P, Singphuoangphet $S$, et al. Epilepsy in Laos: knowledge, attitudes, and practices in the community. Epilepsy Behav 2007; 10:565-70.

15. Fisher RS, Cross JH, French JA, et al. Operational classification of seizure types by the International League Against Epilepsy: position paper of the ILAE Commission for classification and terminology. Epilepsia 2017; 58:522-30.

16. Cramer JA, Perrine K, Devinsky O, Bryant-Comstock L, Meador K, Hermann B. Development and cross-cultural translations of a 31-item quality of life in epilepsy inventory. Epilepsia 1998;39:81-8.

17. Fernandes PT, Salgado PC, Noronha AL, Sander JW, Li LM. Stigma scale of epilepsy: validation process. Arq Neuropsiquiatr 2007;65 Suppl 1: 35-42.

18. Saadi A, Patenaude B, Nirola DK, et al. Quality of life in epilepsy in Bhutan. Seizure 2016;39:44-8.

19. Alanis-Guevara I, Peña E, Corona T, López-Ayala T, López-Meza E, López-Gómez M. Sleep disturbances, socioeconomic status, and seizure control as main predictors of quality of life in epilepsy. Epilepsy Behav 2005; 7:481-5.

20. Ashwin M, Rakesh P, Pricilla RA, Manjunath K, Jacob K, Prasad J. Determinants of quality of life among people with epilepsy attending a secondary care rural hospital in South India. I Neurosci Rural Pract 2013:4(Suppl 1):S62-6.

21. Silva $B$, Canas-Simião $H$, Cordeiro $S$, Velosa $A$, Oliveira-Maia $A$, Barahona-Corrêa JB. Determinants of quality of life in patients with drug-resistant focal epilepsy. Epilepsy Behav 2019;100(Pt A):106525.

22. Shakir M, Al-Asadi JN. Quality of life and its determinants in people with epilepsy in Basrah, Iraq. Sultan Qaboos Univ Med J 2012;12:449-57.

23. Gebre AK, Haylay A. Sociodemographic, clinical variables, and quality of life in patients with epilepsy in mekelle city, northern Ethiopia. Behav Neurol 2018;2018:7593573.

24. Nagarathnam M, Shalini B, Vijayalakshmi V, Vengamma B, Latheef SAA. Predictors of quality of life among adolescents with epilepsy in the state of Andhra Pradesh. Neurol India 2017;65:1019-24.

25. Taylor RS, Sander JW, Taylor RJ, Baker GA. Predictors of health-related quality of life and costs in adults with epilepsy: a systematic review. Epilepsia 2011;52:2168-80.

26. Rakesh PS, Ramesh R, Rachel P, Chanda R, Satish N, Mohan VR. Quality of life among people with epilepsy: a cross-sectional study from rural southern India. Nat/ Med J India 2012;25:261-4.

27. Kim MK. Marital prospects of people with epilepsy among Asians. Neurol Asia 2007;12:13-14.

28. Herodes M, Oun A, Haldre S, Kaasik AE. Epilepsy in Estonia: a quality-of-life study. Epilepsia 2001;42:1061-73.

29. Baker GA, Jacoby A, Buck D, Stalgis C, Monnet D. Quality of life of people with epilepsy: a European study. Epilepsia 1997;38:353-62.

30. Guekht $A B$, Mitrokhina TV, Lebedeva $A V$, et al. Factors influencing on quality of life in people with epilepsy. Seizure 2007;16:128-33. 
31. George J, Kulkarni C, Sarma GRK. Antiepileptic drugs and quality of life in patients with epilepsy: a tertiary care hospital-based study. Value Health Reg Issues 2015;6:1-6.

32. Mroueh L, Boumediene F, Jost J, et al. Quality of life and stigma in Lebanese people with epilepsy taking medication. Epilepsy Res 2020; 167:106437.

33. Nagarathnam M, Vengamma B, Shalini B, Latheef S. Stigma and polytherapy: predictors of quality of life in patients with epilepsy from south India. Ann Indian Acad Neurol 2017;20:233-241.

34. Sawant N, Kinra V. An Indian study on perceptions of patients of epilepsy and their family to stigma and its impact on quality of life. $\mathrm{Am} J \mathrm{Clin}$ Neurol Neurosurgery 2015;1:1-9.

35. Robson C, Myers L, Pretorius C, Lian OS, Reuber M. Health related quality of life of people with non-epileptic seizures: the role of socio-demographic characteristics and stigma. Seizure 2018;55:93-9.
36. Shi Y, Wang S, Ying J, et al. Correlates of perceived stigma for people living with epilepsy: a meta-analysis. Epilepsy Behav 2017;70(Pt A): 198-203.

37. Giuliano L, Cicero CE, Padilla $S$, et al. Knowledge, stigma, and quality of life in epilepsy: results before and after a community-based epilepsy awareness program in rural Bolivia. Epilepsy Behav 2019;92:90-7.

38. Adewumi T, Oladipo E, Adewuya AO. Public perception and attitude towards people living with epilepsy in Nigeria. Epilepsy Behav 2020;106: 107033.

39. Lee HJ, Choi EK, Park HB, Yang SH. Risk and protective factors related to stigma among people with epilepsy: an integrative review. Epilepsy Behav 2020;104(Pt A):106908.

40. Jacoby A, Baker GA. Quality-of-life trajectories in epilepsy: a review of the literature. Epilepsy Behav 2008;12:557-71. 